\title{
Editorial
}

\section{Editorial: How the Words We Use Affect the Care We Deliver}

\author{
David C. Ring MD, PhD, Matthew B. Dobbs MD, Terence J. Gioe MD, \\ Paul A. Manner MD, Seth S. Leopold MD
}

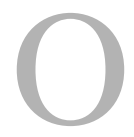

ne moral of the German folk tale, Rumpelstiltskin, is that the act of naming something confers dominion over it. That story also teaches us not to lie to the king or ransom our firstborn child, human values we probably will not return to in future editorials. But its message about the power of language runs so deep that psychologists and trial lawyers have seized upon it; the "Rumpelstiltskin Principle" suggests that titles and names are tools of

The authors certify that they, or any members of their immediate families, have no commercial associations (eg, consultancies, stock ownership, equity interest, patent/ licensing arrangements, etc) that might pose a conflict of interest in connection with the submitted article.

All ICMJE Conflict of Interest Forms for authors and Clinical Orthopaedics and Related Research ${ }^{\mathbb{B}}$ editors and board members are on file with the publication and can be viewed on request.

The opinions expressed are those of the writers, and do not reflect the opinion or policy of $C O R R^{\circledR}$ or The Association of Bone and Joint Surgeons ${ }^{\circledR}$.

D. C. Ring MD, PhD, M. B. Dobbs MD,

T. J. Gioe MD, P. A. Manner MD,

S. S. Leopold MD ( $\varangle)$

Clinical Orthopaedics and Related

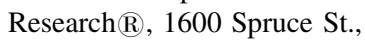

Philadelphia, PA 19103, USA

e-mail: sleopold@clinorthop.org control [1, 2]. We would generalize still further: The way surgeons talk about patients, patients' health conditions, and surgery itself influences those patients, their health, and the operations they undergo.

Specifically, the words surgeons use in scientific writing and daily conversation frame the concepts behind the advice we give patients. Our language needs to reflect our professional values: The patient's own goals should be our focus, and our task is to encourage each patient's self-efficacy. Lapses in language, even inadvertent ones, make it harder to give life to these values, and may bias the advice we provide.

Let's unpack the following opening line from countless indications conferences, repeated with only slight variations in countless research papers:

"The patient failed conservative treatment and required joint replacement."

"Failing" nonoperative treatment implies that surgical treatment is the "success" one might hope to achieve. This conveys that nonoperative treatment is but a stage to pass through-perhaps no more than a perfunctory one - on a road to success, and all roads lead to surgery. Indeed, it suggests that the patient really is incomplete- $\mathrm{a}$ failure-without the intervention the surgeon offers. Used in scientific writing, it tilts the field in favor of invasive treatments, which commonly expose patients to greater risk than do nonsurgical interventions. Used in the office ("I see you've failed pills and shots, perhaps now we should talk about surgery") it carries all those same connotations, along with the additional idea that the patient, who already may be feeling bad for many other reasons, now has in some respect "failed" on this journey despite having done nothing wrong. This does not encourage reflection and adaptation. It encourages a narrow-minded focus on surgery rather than a broad search for plausible options, many of which may be effective and safer. Language like "we offered the patient surgery because he was not satisfied following a reasonable period of supportive treatment" better conveys that surgery is one option among many, and that the patient's own choice is the final arbiter.

Characterizing nonsurgical treatment as "conservative" both obscures meaning and implicitly suggests that surgical alternatives somehow are bolder-and thus perhaps more attractive. While bold might not appeal to all patients, any reaction a patient has to this kind of language would be 


\section{Editorial}

based on emotion, not on facts. And in any case, the term "conservative" as it applies to treatment is entirely contextspecific; for example, fasciotomy is the most-conservative choice for compartmental syndrome. Far better, we think, to describe treatment options in plain terms: Nonsurgical approaches or surgical approaches.

Finally, consider the common description of an operation as "required" (and its evil twin, "necessary"). Few orthopaedic conditions are limb- or life-threatening, and none of the common ones are. Most orthopaedic procedures are elective, and the decision to have surgery is-or at least should be-highly preferencesensitive. The word "required" is not only paternalistic, it conveys a complete absence of options. In scientific reporting, this almost becomes a tautology, a false logic that acculturates surgeons in ways that accentuate their own importance. Readers-and clinicians-come to see "the patient underwent surgery" as synonymous with "the patient required surgery." In fact, they rarely are synonymous. Most surgery is a choice, based on a riskbenefit calculation, and it should be described in terms that reflect this. When we mean "underwent surgery", we should say "underwent surgery"; required orthopaedic procedures are few and far between.

The examples we have shared here do not represent an exhaustive catalogue of the ways surgeons inadvertently shade language in favor of the interventions we perform. But the words we choose do matter. As an editorial staff, will continue to lean on authors to express themselves so as not to suggest surgery is inevitable or necessary unless that truly is the case.

Apart from scientific reporting, it seems important that surgeons' language choices should convey that surgery almost always is discretionary, and that it may be riskier than adapting to a condition with the help of supportive nonsurgical approaches. Most of us would be happy never to "need" surgery, and the language we use-in scientific reporting, orthopaedic education, and clinical care-should celebrate the success associated with avoiding it.

How do you see this important issue? Share your thoughts about the ways that language influences patient care in a letter to the editor to EIC@clinorthop.org.

Acknowledgments The authors thank Lee Beadling BA, Mark C. Gebhardt MD, Raphaël Porcher PhD, Clare M. Rimnac PhD, and Montri D. Wongworawat MD for their thoughtful comments and guiding suggestions during the editorial board meeting that prompted this essay.

\section{References}

1. Brodsky SL. The Rumpelstiltskin principle. In: Testifying in Court: Guidelines and Maxims for the Expert Witness. 2nd ed. Washington, DC: American Psychological Association; 180-182.

2. Van der Geest, S. Rumpelstiltskin: The magic of the right word. In: Oderwald A, van Tilburg W, Neuvel $\mathrm{K}$, eds. Unfamiliar Knowledge: Psychiatric Disorders in Literature. Utrecht, Netherlands: Uitgeverij De Tijdstroom; 37-44. 